\title{
UTILIZAÇÃO DE FÓSFORO E CARACTERÍSTICAS DO SISTEMA RADICULAR E DA PARTE AÉREA DA PLANTA DE ARROZ
}

\author{
EVALDO PACHECO SANT'ANA ${ }^{1}$ \\ EDVALDO VIEIRA PACHECO SANT'ANA ${ }^{2}$ \\ NAND KUMAR FAGERIA ${ }^{1}$ \\ ADELSON DE BARROS FREIRE ${ }^{1}$
}

\begin{abstract}
RESUMO - A seleção de plantas mais eficientes no uso do fósforo é importante para tornar mais econômica a cultura do arroz e, assim, maximizar a produção de grãos. Conduziu-se este trabalho com o objetivo de estudar as inter-relações que possam ocorrer entre a eficiência no uso do $\mathrm{P}$ e outras características da planta do arroz (Oryza sativa L.). Foram avaliados 25 genótipos de terras altas cultivados em solo e in vitro, nos níveis baixo ( $0 \mathrm{mg}^{\mathrm{de}} \mathrm{P} \mathrm{\textrm {dm } ^ { - 3 }}$ ) e alto $(150 \mathrm{mg}$ de $\mathrm{P} \mathrm{dm}$ ${ }^{3}$, em solo, e $17 \mathrm{mg} \mathrm{de} \mathrm{P} \mathrm{dm}^{-3}$ em meio de cultura).
\end{abstract}

Em solo com nível baixo de $\mathrm{P}$, a altura e o número de raízes da planta foram as caraterísticas que tiveram maior efeito direto na eficiência de utilização do $\mathrm{P}$. No nível alto de $\mathrm{P}$, o número de folhas e comprimento das raízes da planta foram as caraterísticas que tiveram maior efeito direto. In vitro, tanto no baixo como no alto nível de $\mathrm{P}$, o teor de $\mathrm{P}$ acumulado e o volume da raiz foram as caraterísticas que tiveram maior efeito direto na eficiência de utilização do P.

TERMOS PARA INDEXAÇÃO: Oryza sativa, correlação, raízes, folhas, fósforo.

\section{PHOSPHORUS UTILIZATION AND CHARACTERISTICS OF ROOT AND TOP OF RICE PLANT}

\begin{abstract}
The improvement of rice plants (Oryza sativa L.) for better $\mathrm{P}$ use efficiency is important to decrease the cost of rice production and maximizing yields. The objective of the present study was to understand the relationship among root and shoot characteristics with $P$ use efficiency and other characteristics of the rice plant. Twenty-five genotypes of rice were grown in soil and in vitro under two level of $\mathrm{P}$ : low $\left(0 \mathrm{mg}\right.$ of $\left.\mathrm{P} \mathrm{dm}^{-3}\right)$ and high $\left(150 \mathrm{mg}\right.$ of $\left.\mathrm{P} \mathrm{dm}^{-3}\right)$
\end{abstract}

in soil, and 0 and $17 \mathrm{mg}$ of $\mathrm{P} \mathrm{dm}^{-3}$ in vitro. In soil at low level of $\mathrm{P}$, the plant height and number of root per plant had the highest direct effect on $\mathrm{P}$ use efficiency. At high $\mathrm{P}$ level, the number of leaves per plant and root length had the highest direct effect on $\mathrm{P}$ use efficiency. In vitro, under all conditions of evaluation and levels of $\mathrm{P}$, the level of $\mathrm{P}$ accumulation in the plant and root volume had the highest direct effect on $\mathrm{P}$ use efficiency.

INDEX TERMS: Oryza sativa, correlation, roots, leaves, phosphorus.

\section{INTRODUÇÃO}

O fósforo é um dos principais nutrientes do arroz e sua deficiência pode afetar a planta, provocando redução no crescimento, no perfilhamento, no sistema radicular e, conseqüentemente, na produtividade (Fageria, 1999).

No Brasil, o arroz de terras altas é cultivado principalmente em solos de cerrados que se caracterizam pela baixa capacidade de retenção de água, alta acidez, baixa disponibilidade de nutrientes, principalmente $\mathrm{N}, \mathrm{P}$, $\mathrm{Ca}$ e $\mathrm{Mg}$. Nesses solos, o $\mathrm{P}$ acha-se fortemente fixado e indisponível para a planta e, assim, altos níveis de fertili- zantes fosfatados são necessários para se produzir nessas condições (Fageria, 1984; Barbosa Filho, 1989).

Há diferenças significativas entre genótipos de arroz na capacidade de absorver e utilizar o P disponível no solo (Sant'Ana, 2000; Furlani \& Furlani, 1991; Clark \& Duncan, 1991; Fageria, 1992). O perfilhamento, a altura da planta e o desenvolvimento radicular são influenciados pelo nível de $\mathrm{P}$ disponível para a planta de arroz (Fageria, 1992). Entretanto, as possíveis associações entre essas características da planta de arroz com sua capacidade de absorver e utilizar o P são, ainda, indefinidas.

\footnotetext{
1. Engenheiro Agrônomo, Dr., Embrapa-Centro Nacional de Pesquisa de Arroz e Feijão (CNPAF), Caixa Postal 179 75375-000 - Santo Antônio de Goiás, GO. fageria@cnpaf.embrapa.br.

2. Engenheiro Agrônomo, M.Sc., Universidade Federal de Goiás (UFG), Caixa Postal 131 - 74001-970 - Goiânia, GO.
} 
Furlani et al. (1983) constataram que em condições de baixa disponibilidade de $\mathrm{P}$ em solução nutritiva, a massa da parte aérea e das raízes secas foram as características que mais se relacionaram com a eficiência de utilização de $\mathrm{P}$ e permitiram a diferenciação de genótipos de arroz. Fageria et al. (1988), trabalhando com quatro níveis de $\mathrm{P}$, observaram que os genótipos de arroz variaram consideravelmente na capacidade de extração do $\mathrm{P}$ do solo e que a produção de massa da parte aérea e grãos secos foram as características que possibilitaram a distinção entre eles em eficientes e nãoeficientes.

A produção de massa de grãos secos e os componentes de produção foram significativamente aumentados com a aplicação de $\mathrm{P}$ e a produção de grãos aumentou até a dose de $150 \mathrm{mg}$ de $\mathrm{P} \mathrm{kg}^{-1}$ do solo (Fageria, 1991).

A obtenção de plantas de arroz mais eficientes na utilização do P é a maneira mais econômica de se reduzir os custos de produção dessa cultura, especialmente nas condições de cerrado (Clark \& Duncan, 1991; Fageria, 1992). O conhecimento das associações dessa eficiência com outras características da planta do arroz é de grande importância no melhoramento desse cereal e o parâmetro que melhor define essas relações é o coeficiente de correlação genotípica, que é isento de efeito ambiental (Venkovski \& Barriga, 1992). Esse coeficiente mede o grau com que as duas variáveis estão associadas mediante a quantidade de variação de um dado caracter que pode ser explicado pela função linear de um outro (Gomez \& Gomez, 1976).

Objetivou-se com este trabalho determinar as possíveis associações que possam ocorrer entre a eficiência no uso de P e outras características da planta de arroz.

\section{MATERIAL E MÉTODOS}

Os experimentos foram conduzidos em solo (condição S), em casa-de-vegetação e in vitro (condição V) no Laboratório de Biotecnologia da Embrapa Arroz e Feijão, em Santo Antônio de Goiás, GO. No experimento em solo, as plantas desenvolveram-se em vasos com $0,75 \mathrm{~kg}$ de um Latossolo Vermelho-Escuro, textura argilosa (LE), cuja análise química $(0-20 \mathrm{~cm})$ da amostra revelou os seguintes resultados: $\mathrm{pH}\left(\mathrm{H}_{2} \mathrm{O}\right)=5,3$; M.O. $=27 \mathrm{~g} \mathrm{~kg}^{-1} ; \mathrm{Ca}=0,9 \mathrm{cmol}_{\mathrm{c}} \mathrm{dm}^{-3} ; \mathrm{Mg}=0,4 \mathrm{cmol}_{\mathrm{c}}$ $\mathrm{dm}^{-3} ; \mathrm{Al}=0,8 \mathrm{cmol}_{\mathrm{c}} \mathrm{dm}^{-3} ; \mathrm{P}=0,3 \mathrm{mg} \mathrm{dm}^{-3} ; \mathrm{K}=48 \mathrm{mg}$ $\mathrm{dm}^{-3} ; \mathrm{Cu}=2,0 \mathrm{mg} \mathrm{dm}^{-3} ; \mathrm{Zn}=0,6 \mathrm{mg} \mathrm{dm}^{-3} ; \mathrm{Fe}=138 \mathrm{mg}$ $\mathrm{dm}^{-3}$ e $\mathrm{Mn}=7,0 \mathrm{mg} \cdot \mathrm{dm}^{-3}$.
$\mathrm{O} \mathrm{Ca}, \mathrm{Mg}$ e $\mathrm{Al}$ foram extraídos com solução de 1 mol $\mathrm{L}^{-1} \mathrm{KCl}$, sendo o $\mathrm{Ca}$ e o $\mathrm{Mg}$ determinados por titulação de EDTA, e o Al, por titulação de $\mathrm{NaOH}$. O P e o $\mathrm{K}$ foram extraídos pelo extrator Mehlich $1\left(0,05 \mathrm{~mol} \mathrm{~L}^{-1}\right.$ $\left.\mathrm{HCl}+0,0125 \mathrm{~mol} \mathrm{~L}^{-1} \mathrm{H}_{2} \mathrm{SO}_{4}\right)$ e determinados por colorímetro e fotômetro de chama, respectivamente. Os micronutrientes foram determinados na mesma solução do P, por absorção atômica, e a matéria orgânica (M.O.), pelo método de Walkley e Black (Embrapa, 1997).

No experimento em solo, os tratamentos de $\mathrm{P}$ fo-

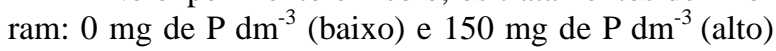
do solo (super triplo). Cada vaso recebeu $80 \mathrm{mg}$ de $\mathrm{N}$ $\left[\left(\mathrm{NH}_{4}\right)_{2} \mathrm{SO}_{4}\right], 10 \mathrm{mg}$ de $\mathrm{K}(\mathrm{KCl})$ e $75 \mathrm{mg}$ de FTE-BR-12 como fonte de micronutrientes. Foram semeadas dez sementes por vaso. Após dez dias da semeadura, foi realizado o desbaste, deixando-se cinco plantas por vaso. As plantas invasoras foram retiradas manualmente, não tendo sido observados ataques de pragas e doenças que justificassem seu controle químico. Foram efetuadas duas irrigações diárias, sendo uma pelo manhã e outra, no final da tarde.

No experimento in vitro, foi utilizado o meio de cultura MS modificado (Murashige \& Skoog, 1962) para cultura de embriões, suplementado com $30 \mathrm{~g} \mathrm{~L}^{-1}$ de sacarose, 2,0 $\mathrm{mg} \mathrm{L}^{-1}$ de glicina, $0,5 \mathrm{mg} \mathrm{L}^{-1}$ de ácido nicotínico, $0,5 \mathrm{mg} \mathrm{L}^{-1}$ de pirodoxina e $0,1 \mathrm{mg} \mathrm{L}^{-1}$ de tiamina.

$\mathrm{O} \mathrm{P}$ foi adicionado ao meio de cultura na forma de fosfato monobásico de potássio $\left(\mathrm{KH}_{2} \mathrm{PO}_{4}\right)$. As dosagens utilizadas do produto foram 0 e $17 \mathrm{mg} \mathrm{dm}^{-3}$ de $\mathrm{P}$, que correspondem ao baixo e ao alto nível de $\mathrm{P}$.

Após o ajuste do pH para 5,8 com $\mathrm{NaOH}(0,5$ $\mathrm{N}$ ), o meio foi solidificado com Phytagel $\left(5 \mathrm{~g} \mathrm{~L}^{-1}\right) \mathrm{e}$ submetido à autoclavagem por 15 minutos, à uma temperatura de $120^{\circ} \mathrm{C}$ e pressão de $1,5 \mathrm{~atm}$.

Sementes das cultivares/linhagens foram descascadas manualmente (eliminação da lema e pálea) e, em seguida, foram desinfestadas em uma solução de álcool etílico $70 \%$ durante dois minutos. Uma segunda desinfestação foi feita usando uma solução de hipoclorito de sódio a $3 \%$, na qual permaneceram por 25 minutos. A seguir, as sementes foram lavadas quatro vezes em água destilada e esterilizada e, depois, colocadas em placas de Petri com água destilada, onde permaneceram durante 20 horas.

A excisão dos embriões foi feita utilizando bisturi submergido em álcool etílico a $70 \%$ e flambado antes de cada operação. Os embriões foram cuidadosamente seccionados e imediatamente transferidos para o meio de cultura em magentas com capacidade de $650 \mathrm{~cm}^{3}$, contendo $40 \mathrm{ml}$ de meio de cultura. Em se- 
guida, as magentas foram vedadas com parafilme e incubadas em câmara de crescimento a uma temperatura de $26^{\circ} \mathrm{C}$ e fotoperíodo de 16 horas de luz. Os da- dos foram coletados de cinco plantas, sendo, portanto, descartadas duas plantas por magenta.

Em ambos os experimentos, foram utilizados 25 genótipos de arroz de terras altas (Tabela 1).

TABELA 1 - Nome, origem, tipo de planta e número de identificação das cultivares e linhagens de arroz (Oryza sativa) de terras altas utilizadas nos experimentos conduzidos em solo e in vitro.

\begin{tabular}{|c|c|c|c|}
\hline Cultivares e linhagens & Origem & Tipo de planta & Identificação da Embrapa \\
\hline ITA 235 & Nigéria & Tradicional & CNA 3178 \\
\hline Rio Paranaíba & Brasil & Tradicional & CNA 4120 \\
\hline Guarani & Brasil & Tradicional & CNA 4121 \\
\hline CNA 444-B38-7-B-4 & Brasil & Tradicional & CNA 4178 \\
\hline CNA 425-BM46-1-B-1 & Brasil & Tradicional & CNA 4181 \\
\hline № 7452 Chianan8 X Kagoshima Hakamuri 1 & Coréia & Tradicional & CNA 4474 \\
\hline TOX 1785-19-18 & Nigéria & Tradicional & CNA 4640 \\
\hline L $80-67$ & Costa do Marfim & Tradicional & CNA 5021 \\
\hline CNA 095-BM30-BM27P-15-2 & Brasil & Tradicional & CNA 5164 \\
\hline CNA 095-BM30-BM27P-17-2 & Brasil & Tradicional & CNA 5165 \\
\hline Douradão & Brasil & Tradicional & CNA 5166 \\
\hline Caiapó & Brasil & Tradicional & CNA 6187 \\
\hline Carajás & Brasil & Tradicional & CNA 6710 \\
\hline СТ 6949-2-3-3-1-B & Colômbia & Não tradicional & CNA 7460 \\
\hline Canastra & Brasil & Não tradicional & CNA 7475 \\
\hline СТ 6196-33-2-6-B & Colômbia & Não tradicional & CNA 7755 \\
\hline Progresso & Brasil & Não tradicional & CNA 7937 \\
\hline Primavera & Brasil & NãoTradicional & CNA 8070 \\
\hline Carisma & Brasil & Não tradicional & CNA 8305 \\
\hline CT 11251-7-2-M-1-M-M & Colômbia & Não tradicional & CNA 8436 \\
\hline Maravilha & Brasil & Não radicional & CNA 8533 \\
\hline CNAx 4883-7-M-M2-9 & Colômbia & Tradicional & CNA 8693 \\
\hline CNAx 4914-78-M-M-8 & Colômbia & Tradicional & CNA 8705 \\
\hline 3A-79-BRM2-M-M2-3 & Brasil & Tradicional & CNA 8707 \\
\hline CNAx 4914-36-M-M-3 & Brasil & Tradicional & CNA 8711 \\
\hline
\end{tabular}

Ciênc. agrotec., Lavras. V.27, n.2, p.370-381, mar./abr., 2003 
O experimento foi um fatorial disposto em delineamento de blocos completos casualizados com 25 cultivares em dois níveis de $\mathrm{P}$ e três repetições, sendo utilizada a média dos genótipos para cada variável estudada. Os coeficientes de correlações e análises de trilha (path analysis) foram obtidos pelo programa Genes.

Os dados foram coletados após 25 dias, a contar da data de emergência das plântulas. Na colheita, as plantas tiveram suas raízes lavadas cuidadosamente em água corrente para eliminação do solo ou meio de cultura. Foram tomados os seguintes dados: altura da planta (AP) - medida da ponta da folha mais longa ao colo da planta; número de perfilhos (NP) - total de perfilhos por planta; número de folhas (NF) - total do número de folhas por planta; comprimento das raízes (CR) - medido

\section{Eficiência de utilização de $\mathbf{P}$ (EU)}

\section{RESULTADOS E DISCUSSÃO}

Uma visão mais detalhada da associação entre variáveis é dada pela análise de trilha (path analysis), que permite o desdobramento dos coeficientes de correlação, mostrando os efeitos diretos e indiretos das variáveis sobre uma outra dependente.

$\mathrm{Na}$ condição $\mathrm{S}$, no baixo nível de $\mathrm{P}$, a variável AP teve o maior efeito direto sobre $\operatorname{EU}(0,886)$, sendo esse efeito positivo (Figura 1). Isso significa que a seleção de plantas de maior AP levará a um aumento da EU, e isso é confirmado pela correlação positiva $(0,393)$ entre AP e EU (Tabela 2). A maioria das cultivares/linhagens usadas nesse experimento é do tipo tradicional de arroz de terras altas, que se caracterizam pelo porte alto, baixo perfilhamento e folhas longas. Esses materiais são adaptados às condições adversas dos solos de cerrado e têm mostrado serem eficientes na extração do $\mathrm{P}$ em solos pobres desse nutriente (Fageria et al., 1988; Fageria \& Barbosa Filho, 1982). Entretanto, no nível alto de $\mathrm{P}$, a variável $\mathrm{NF}$ teve o maior efeito direto sobre EU $(1,618)$ mostrando que, nessas condições, plantas de arroz com maior NF serão mais eficientes na utilização de $\mathrm{P}$ (Figura 2). O efeito indireto de NF sobre EU via AP e NP foi negativo (-0,391), praticamente anulando seu efeito direto e resultando na ausência de associação entre essa característica e EU (Tabela 3). O alto valor negativo obtido indiretamente pela NP é indicativo de que plantas menos perfilhadoras terão maior EU nessas condições. As cultivares de terras altas têm, geralmente, menor capacidade de perfilhamento e isso de- do colo da planta até a ponta da raiz mais longa; número de raízes (NR) - número total de raízes por planta; diâmetro da raiz (DR) - medido na porção mediana da raiz mais longa; volume médio das raízes (VR) - medido pelo deslocamento de água provocado pela introdução das raízes em uma proveta graduada.

Na determinação do teor e acúmulo de $\mathrm{P}$ (AC), as plantas foram secas em estufa a $70^{\circ}-80^{\circ} \mathrm{C}$ durante 72 horas. Em seguida, foram pesadas e moídas em moinho equipado com peneira de malha de 20 "meshes". A digestão foi feita com uma mistura de 2:1 de ácido nítrico e perclórico (Moraes \& Rabelo, 1986) e o P, determinado pelo método colorimétrico (Yoshida et al., 1976).

A eficiência de utilização de $\mathrm{P}$ pela planta (EU) foi determinada pela fórmula:

\section{Matéria seca da parte aérea (mg)}

\section{Acumulação de $P$ na parte aérea $(\mathrm{mg})$}

ve estar associado a sua adaptação às condições deficientes em nutrientes do sistema de terras altas. Entretanto, Sant'Ana (2000) obteve diferenças significativas para o perfilhamento entre níveis de $\mathrm{P}$ em arroz de terras altas, o que mostra a capacidade de resposta dessas cultivares ao nutriente. $\mathrm{O} \mathrm{P}$ aumenta o número de perfilhos dos cereais em geral e, com isso, o número de panículas e, conseqüentemente, desempenha um importante papel na produção de grãos (Barbosa Filho, 1989).

Na condição $\mathrm{V}$, e em ambos os níveis de $\mathrm{P}$, a variável $\mathrm{AC}$ apresentou o maior efeito direto e negativo sobre EU (Figuras 1 e 2). Isso indica que a seleção de plantas com maior AC levará a uma redução na EU nas condições desses experimentos. Assim, plantas com alta concentração de $\mathrm{P}$ na parte aérea terão menor EU, e isso é confirmado pelas correlações negativas obtidas entre AC e EU (Tabelas 2, 3 e 5). A máxima eficiência do uso de $\mathrm{P}$ é dependente do seu nível crítico, acima do qual essa eficiência decai (Fageria, 1992). As cultivares avaliadas, embora eficientes na extração de $\mathrm{P}$ em solos pobres nesse elemento, não apresentaram alta eficiência no seu uso nas condições in vitro. Isso provavelmente ocorreu por não haver fixação do fósforo no meio de cultura in vitro e, conseqüentemente, existir uma maior disponibilidade do elemento para a planta (Caldas et al., 1998). Essa maior disponibilidade pode provocar um desequilíbrio na relação absorção/crescimento da planta, resultando numa associação negativa entre AC e EU (Sant'Ana, 2000; Fageria, 1992). 
TABELA 2 - Coeficientes de correlações genéticas entre as variáveis altura da planta (AP), número de folhas por planta (NF), número de perfilhos por planta (NP), teor de $\mathrm{P}$ acumulado na planta (AC), comprimento de raiz (CR), número de raízes (NR), diâmetro da raiz (DR), volume das raízes (VR) e eficiência na utilização do $\mathrm{P}$ (EU) em plantas de arroz em solo com baixo nível de $\mathrm{P}$.

\begin{tabular}{ccccccccc}
\hline & $\mathbf{N F}$ & $\mathbf{N P}$ & $\mathbf{A C}$ & $\mathbf{C R}$ & $\mathbf{N R}$ & $\mathbf{D R}$ & $\mathbf{V R}$ & $\mathbf{E U}$ \\
\hline AP & $-0,520$ & $-0,433$ & 0,328 & $-0,010$ & $-0,447$ & 0,317 & 0,258 & 0,393 \\
NF & & 0,359 & 0,619 & 0,103 & 0,591 & $-0,300$ & $-0,672$ & $-0,684$ \\
NP & & & 0,061 & 0,478 & $-0,178$ & 0,533 & $-0,246$ & $-0,122$ \\
AC & & & & 0,250 & 0,818 & $-0,721$ & $-0,200$ & $-0,408$ \\
CR & & & & & $-0,255$ & $-0,229$ & 0,095 & $-0,093$ \\
NR & & & & & & $-0,322$ & $-0,212$ & $-0,717$ \\
DR & & & & & & & 0,035 & 0,571 \\
VR & & & & & & & & $-0,186$ \\
\hline
\end{tabular}

TABELA 3 - Coeficientes de correlações genéticas entre as variáveis altura da planta (AP), número de folhas por planta (NF), número de perfilhos por planta (NP), teor de $\mathrm{P}$ acumulado na planta (AC), comprimento de raiz (CR), número de raízes (NR), diâmetro da raiz (DR), volume das raízes (VR) e eficiência na utilização do $\mathrm{P}$ (EU) em planta de arroz em solo com alto nível de P.

\begin{tabular}{ccccccccc}
\hline & $\mathbf{N F}$ & $\mathbf{N P}$ & $\mathbf{A C}$ & $\mathbf{C R}$ & $\mathbf{N R}$ & $\mathbf{D R}$ & $\mathbf{V R}$ & $\mathbf{E U}$ \\
\hline AP & $-0,391$ & $-0,253$ & $-0,141$ & 0,773 & $-0,495$ & 0,371 & 0,134 & 0,507 \\
NF & & 0,968 & 0,075 & $-0,095$ & 0,334 & $-0,127$ & 0,206 & $-0,140$ \\
NP & & & 0,497 & $-0,059$ & 0,134 & 0,019 & 0,259 & $-0,153$ \\
AC & & & & 1,115 & $-0,397$ & $-0,264$ & $-0,065$ & $-0,782$ \\
CR & & & & & $-0,467$ & 0,862 & 0,632 & 0,484 \\
NR & & & & & & $-0,276$ & 0,166 & 0,213 \\
DR & & & & & & & 0,729 & 0,167 \\
VR & & & & & & & & 0,370 \\
\hline
\end{tabular}

Das características radiculares, a variável NR apresentou o maior efeito direto e negativo $(-0,737)$ sobre EU na condição $\mathrm{S}$ e no nível baixo de $\mathrm{P}$ (Figura 3). Entretanto, no nível alto de P, foi a característica $\mathrm{CR}$ quem apresentou maior efeito direto e positivo $(2,106)$ sobre EU (Figura 4). Seu efeito indireto via DR foi de alto valor e associado aos efeitos indiretos via NR e VR resultando na correlação positiva $(0,484)$ entre CR e EU (Tabela 3$)$. Assim, na condição $\mathrm{S}$ e alto nível de $\mathrm{P}$, plantas com raízes mais longas foram mais eficientes na utilização desse nutriente. $\mathrm{O}$ alto efeito indireto e negativo de CR via DR indicam que raízes mais finas favorecerão um maior EU nessa condição. Isso também é confirmado pelo alto efeito indireto e positivo $(1,817)$ de DR via CR sobre EU. Geralmente, as cultivares melhoradas de arroz de terras altas brasileiras tendem a ter raízes mais finas quando comparadas com as tradicionais (Sant'Ana, 1994). Por outro lado, na condição de baixa disponibilidade de um nutriente, é vantajoso para a planta ter um sistema radicular com maior número de raízes, o que permite explorar o solo com maior eficiência. En-

Ciênc. agrotec., Lavras. V.27, n.2, p.370-381, mar./abr., 2003 
tretanto, em condições de maior disponibilidade de $\mathrm{P}$ no solo, raízes mais longas possibilitam a planta extrair, além de nutrientes, água das camadas mais pro- fundas, o que é fundamental em arroz de terras altas (Fageria, 1992; Chang et al., 1982).
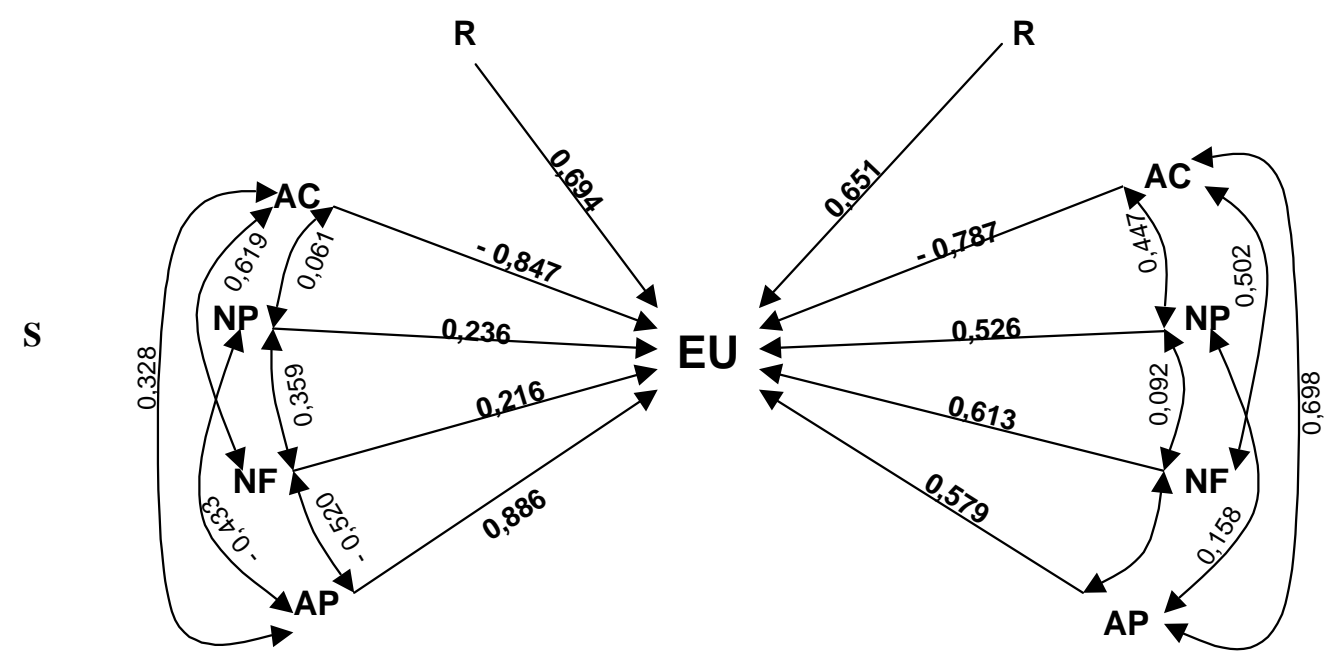

\section{$\mathbf{V}$}

Efeitos indiretos das variáveis

\begin{tabular}{lllll}
\multicolumn{1}{c}{$\mathbf{S}$} & & \multicolumn{1}{c}{$\mathbf{V}$} \\
Variável $=======$ AP & & Variável ======> AP & \\
Efeito indireto via NF & $-0,112$ & & Efeito indireto via NF & $-0,064$ \\
Efeito indireto via NP & $-0,02$ & & Efeito indireto via NP & $-0,015$ \\
Efeito indireto via AC & $-0,278$ & & Efeito indireto via TA & 0,374 \\
Variável =======> NF & & Variável =======> NF & \\
Efeito indireto via AP & $-0,460$ & Efeito indireto via AP & 0,034 \\
Efeito indireto via NP & 0,084 & Efeito indireto via NP & $-0,008$ \\
Efeito indireto via AC & $-0,524$ & Efeito indireto via TA & 0,637 \\
Variável =======> NP & & Variável ======> NP & \\
Efeito indireto via AP & $-0,383$ & Efeito indireto via AP & 0,012 \\
Efeito indireto via NF & 0,077 & Efeito indireto via NF & $-0,013$ \\
Efeito indireto via AC & $-0,051$ & Efeito indireto via TA & 0,419 \\
Variável =======> AC & & Variável =======> AC & \\
Efeito indireto via AP & 0,290 & Efeito indireto via AP & $-0,027$ \\
Efeito indireto via NF & 0,133 & Efeito indireto via NF & 0,087 \\
Efeito indireto via NP & 0,014 & Efeito indireto via NP & 0,037
\end{tabular}

FIGURA 1 - Inter-relações entre as variáveis altura da planta (AP), número de folhas (NF), número de perfilhos (NP) e P acumulado na planta (AC) e seus efeitos diretos e indiretos na eficiência de utilização do P (EU) pela planta de arroz em nível baixo de $\mathrm{P}$ em solo (S) e in vitro (V). 


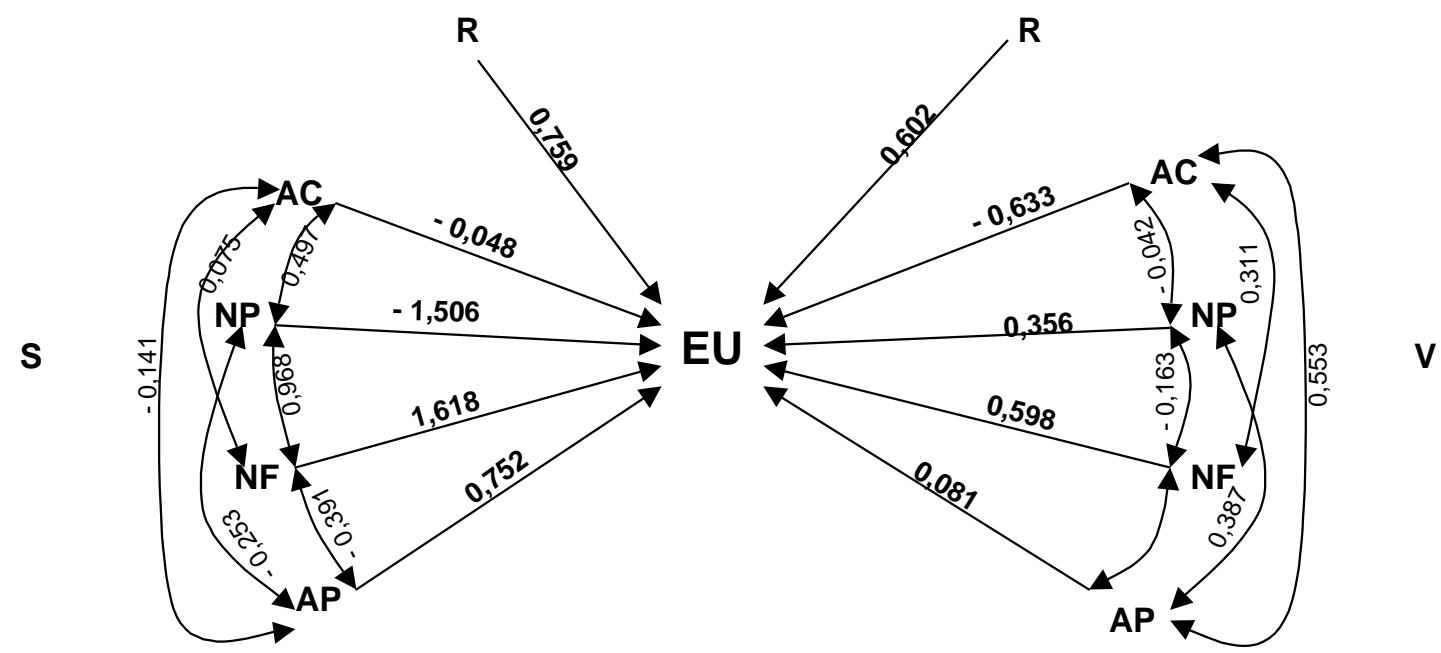

Efeitos indiretos das variáveis

\begin{tabular}{lcll}
\multicolumn{1}{c}{$\mathbf{S}$} & & & \multicolumn{2}{c}{$\mathbf{V}$} \\
Variável =======> AP & & Variável ======> AP & \\
Efeito indireto via NF & 0,014 & Efeito indireto via NF & 0,420 \\
Efeito indireto via NP & $-0,043$ & Efeito indireto via NP & 0,180 \\
Efeito indireto via AC & 0,444 & Efeito indireto via AC & 0,494 \\
Variável =======> NF & & Variável =======>NF & \\
Efeito indireto via AP & $-0,035$ & Efeito indireto via AC & $-0,559$ \\
Efeito indireto via NP & 0,166 & Efeito indireto via NP & $-0,076$ \\
Efeito indireto via AC & $-0,232$ & Efeito indireto via AC & 0,419 \\
Variável =======>NP & & Variável =======>NP & \\
Efeito indireto via AP & $-0,023$ & Efeito indireto via AP & $-0,317$ \\
Efeito indireto via NF & $-0,036$ & Efeito indireto via NF & $-0,100$ \\
Efeito indireto via AC & $-0,265$ & Efeito indireto via AC & 0,269 \\
Variável =======>AC & & Variável =======>AC & \\
Efeito indireto via AP & $-0,041$ & Efeito indireto via AP & 0,38 \\
Efeito indireto via NF & $-0,009$ & Efeito indireto via NF & $-0,279$ \\
Efeito indireto via NP & 0,046 & Efeito indireto via NP & $-0,135$
\end{tabular}

FIGURA 2 - Inter-relações entre as variáveis altura da planta (AP), número de folhas (NF), número de perfilhos (NP) e P acumulado na planta (AC) e seus efeitos diretos e indiretos na eficiência de utilização do P (EU) pela planta de arroz em nível alto de $\mathrm{P}$ em solo (S) e in vitro (V). 


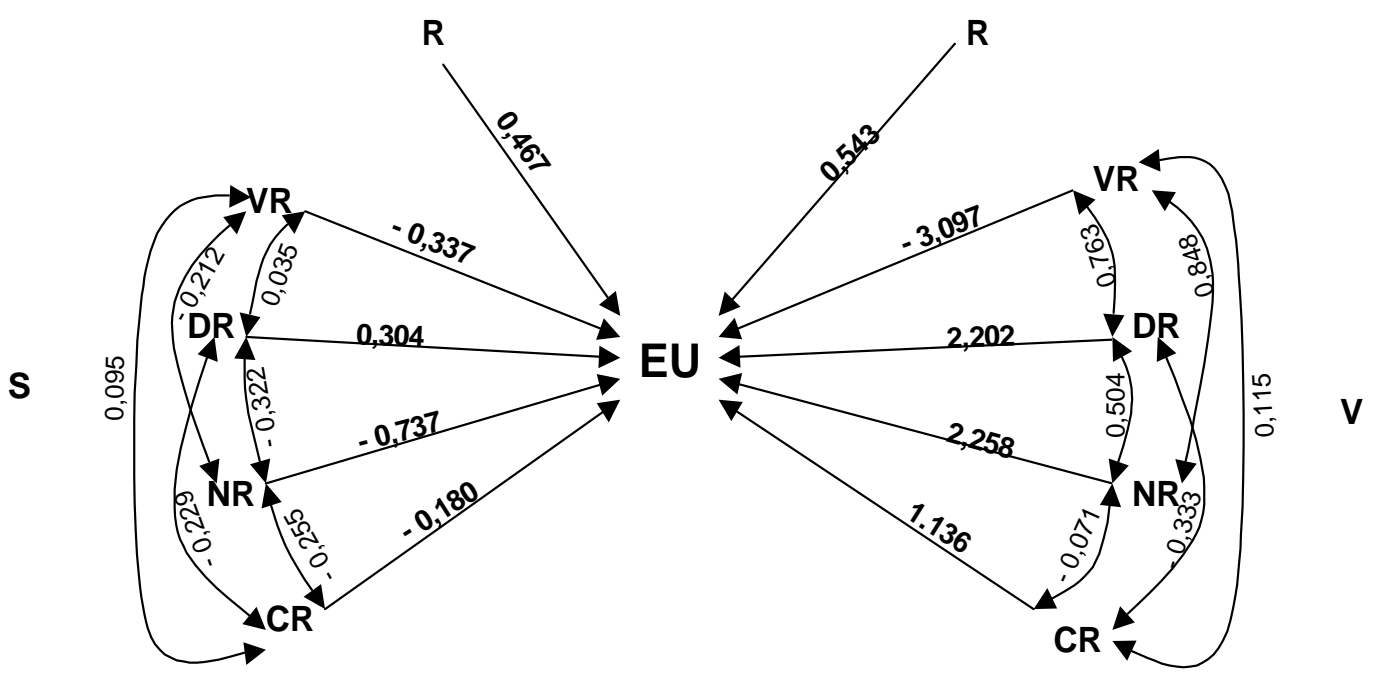

Efeitos indiretos das variáveis

S

Variável =======>CR

Efeito indireto via NR

Efeito indireto via DR

0,188

$-0,069$

Efeito indireto via VR $\quad-0,032$

Variável $=======>\mathrm{NR}$

Efeito indireto via $\mathrm{CR}$

0,046

Efeito indireto via DR $\quad-0,098$

Efeito indireto via VR $\quad 0,071$

Variável $=======>$ DR

Efeito indireto via CR $\quad 0,041$

Efeito indireto via NR $\quad 0,237$

Efeito indireto via VR $\quad-0,011$

Variável =======> VR

Efeito indireto via $\mathrm{CR}$

Efeito indireto via NR

$-0,017$

0,156

Efeito indireto via DR $\quad 0,010$

\begin{tabular}{|c|c|c|}
\hline \\
\hline \multicolumn{3}{|c|}{ Variável $=======>C R$} \\
\hline Efeito indireto via & & $-0,161$ \\
\hline Efeito indireto via & & $-0,733$ \\
\hline Efeito indireto via & & $-0,358$ \\
\hline \multicolumn{3}{|c|}{ Variável $=======>\mathrm{NR}$} \\
\hline Efeito indireto via & CR & $-0,081$ \\
\hline Efeito indireto via & DR & 1,110 \\
\hline Efeito indireto via & VR & $-2,629$ \\
\hline \multicolumn{3}{|c|}{ Variável =======>DR } \\
\hline Efeito indireto via & $\mathrm{CR}$ & $-0,378$ \\
\hline Efeito indireto via & NR & 1,138 \\
\hline Efeito indireto via & VR & $-2,365$ \\
\hline \multicolumn{3}{|c|}{ Variável $=======>$ VR } \\
\hline Efeito indireto via & CR & 0,131 \\
\hline Efeito indireto via & NR & 1,916 \\
\hline Efeito indireto via & DR & 1,682 \\
\hline
\end{tabular}

FIGURA 3 - Inter-relações entre as variáveis comprimento da raiz (CR), número de raízes (NR), diâmetro da raiz (DR) e volume da raiz (VR) e seus efeitos diretos e indiretos na eficiência de utilização do P (EU) pela planta de arroz em nível baixo de $\mathrm{P}$ em solo $(\mathrm{S})$ e in vitro $(\mathrm{V})$.

Na condição $\mathrm{V}$, no baixo nível de $\mathrm{P}$, a característica de maior efeito direto sobre EU $(-3,097)$ foi VR e esse efeito foi negativo (Figura 3).
Os efeitos indiretos de VR sobre EU via NR e DR foram altos e positivos, o que contrabalançou o alto efeito direto e negativo dessa variável, resultando uma 
correlação positiva com EU (Tabela 4). Isto mostra que, embora o coeficiente de correlação entre VR e EU seja alto e positivo, isso foi devido somente aos efeitos indiretos de CR, NR e DR, que foram positivos e de alto valor. Assim, a seleção de plantas com maior VR, conseqüentemente, reduzirá a EU, o que não é desejável. Entretanto, a seleção de plantas com maior CR, NR e DR anulará esse efeito negativo de VR, provocando, assim, um aumento da EU.

No alto nível de $\mathrm{P}$, a variável de maior efeito direto sobre EU foi, também, VR (1,543); porém, nesse caso, o efeito foi positivo (Figura 4). Os seus efeitos indiretos via CR, NR e DR foram negativos, resultando na correlação positiva entre VR e EU (Tabela 5). Os efeitos diretos das outras variáveis foram todos negativos, significando que, em um ambiente de alta disponibilidade de $\mathrm{P}$, essas características interagem de maneira contrária quando em um ambiente carente desse macronutriente. Assim, na condição V e em um ambiente de alta disponibilidade de $\mathrm{P}$, a seleção de plantas com maior VR levará a um aumento de EU. Entretanto, as raízes tenderão a ter menor CR, NR e DR. Sant'Ana (2000) constatou que as características radiculares variam de acordo com o meio e a dose de P utilizada. Embora tenha sido relatado que o maior diâmetro da raiz é uma característica importante no arroz de terras altas, devido a sua maior capacidade de penetrar no solo e extrair água das camadas mais profundas (IITA, 1982), Sant'Ana (1994) observou que as cultivares modernas de arroz de terras altas brasileiras têm, em média, raízes mais longas e finas que as tradicionais.

TABELA 4 - Coeficientes de correlações genéticas entre as variáveis altura da planta (AP), número de folhas por planta (NF), número de perfilhos por planta (NP), teor de $\mathrm{P}$ acumulado na planta (AC), comprimento de raiz (CR), número de raízes (NR), diâmetro da raiz (DR), volume das raízes (VR) e eficiência na utilização do $\mathrm{P}$ (EU) em planta de arroz in vitro em baixo nível de $\mathrm{P}$.

\begin{tabular}{|c|c|c|c|c|c|c|c|c|}
\hline & NF & NP & $\mathrm{AC}$ & CR & NR & DR & VR & $\mathbf{E U}$ \\
\hline AP & 0,427 & 0,158 & 0,698 & 0,186 & 0,612 & 0,688 & 0,800 & 0,375 \\
\hline $\mathrm{NF}$ & & 0,092 & 0,502 & $-0,288$ & 0,667 & 0,364 & 0,557 & 0,513 \\
\hline NP & & & 0,447 & 0,205 & 0,535 & $-0,180$ & 0,403 & 0,323 \\
\hline $\mathrm{AC}$ & & & & 0,207 & 0,597 & 0,380 & 0,768 & 0,161 \\
\hline CR & & & & & $-0,071$ & $-0,333$ & 0,115 & $-0,117$ \\
\hline NR & & & & & & 0,504 & 0,848 & 0,658 \\
\hline DR & & & & & & & 0,763 & 0,596 \\
\hline VR & & & & & & & & 0,633 \\
\hline
\end{tabular}

Ciênc. agrotec., Lavras. V.27, n.2, p.370-381, mar./abr., 2003 

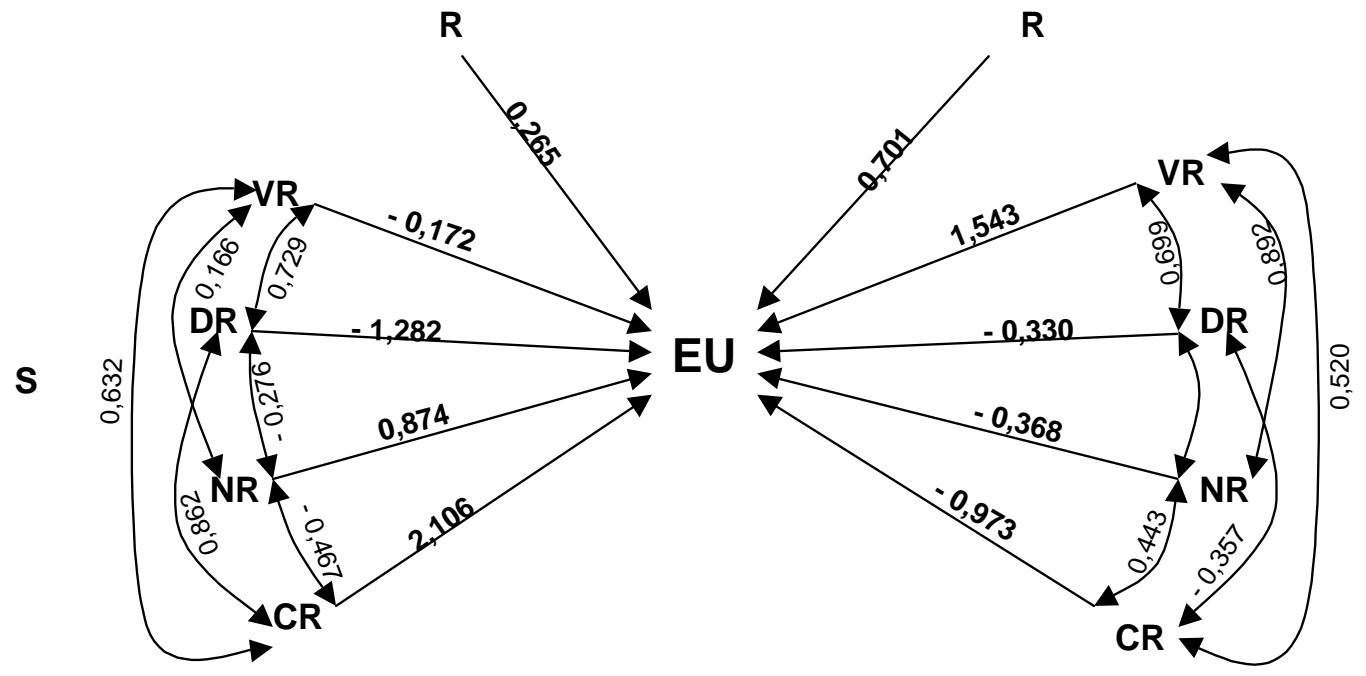

Efeitos indiretos das variáveis

$\mathbf{S}$

Variável =======> CR

Efeito indireto via NR

Efeito indireto via DR

Efeito indireto via VR

Variável $=======>\mathrm{NR}$

Efeito indireto via CR $\quad-0,985$

Efeito indireto via DR

Efeito indireto via VR

0,354

$-0,028$

Variável =======> DR

Efeito indireto via $\mathrm{CR}$

1,816

Efeito indireto via NR

Efeito indireto via VR

$-0,125$

Variável $=======>$ VR

Efeito indireto via $\mathrm{CR}$

Efeito indireto via NR

0,145

Efeito indireto via DR
V

Variável $=======>\mathrm{CR}$

Efeito indireto via NR

$-0,163$

Efeito indireto via DR

0,118

Efeito indireto via VR

0,803

Variável $=======>\mathrm{NR}$

Efeito indireto via CR $\quad-0,431$

Efeito indireto via DR $\quad-0,187$

Efeito indireto via VR $\quad 1,376$

Variável $=======>D R$

Efeito indireto via CR $\quad 0,347$

Efeito indireto via NR $\quad-0,208$

Efeito indireto via VR $\quad 1,078$

Variável $=======>\mathrm{VR}$

Efeito indireto via CR $\quad-0,506$

Efeito indireto via NR $\quad-0,328$

Efeito indireto via DR $\quad-0,230$

FIGURA 4 - Inter-relações entre as variáveis comprimento da raiz (CR), número de raízes (NR), diâmetro da raiz (DR) e volume da raiz (VR) e seus efeitos diretos e indiretos na eficiência de utilização do P (EU) pela planta de arroz em nível alto de $\mathrm{P}$ em solo $(\mathrm{S})$ e in vitro $(\mathrm{V})$. 
TABELA 5 - Coeficientes de correlações genéticas entre as variáveis altura da planta (AP), número de folhas por planta (NF), número de perfilhos por planta (NP), teor de $\mathrm{P}$ acumulado na planta (AC), comprimento de raiz (CR), número de raízes (NR), diâmetro da raiz (DR), volume das raízes (VR) e eficiência na utilização do $\mathrm{P}$ (EU) em planta de arroz in vitro em alto nível de $\mathrm{P}$.

\begin{tabular}{ccccccccc}
\hline & NF & NP & AC & CR & NR & DR & VR & EU \\
\hline AP & 0,684 & 0,387 & 0,553 & 0,447 & 0,825 & 0,541 & 0,813 & 0,278 \\
NF & & $-0,163$ & 0,311 & 0,273 & 0,506 & 0,510 & 0,814 & 0,398 \\
NP & & & $-0,042$ & 0,299 & 0,125 & 0,197 & 0,154 & 0,316 \\
AC & & & & 0,952 & 0,487 & $-0,302$ & 0,490 & $-0,417$ \\
CR & & & & & 0,443 & $-0,357$ & 0,520 & $-0,214$ \\
NR & & & & & & 0,566 & 0,892 & 0,389 \\
DR & & & & & & & 0,699 & 0,888 \\
VR & & & & & & & & 0,477 \\
\hline
\end{tabular}

\section{CONCLUSÕES}

a) Os efeitos diretos e indiretos de cada variável sobre a eficiência na utilização do $\mathrm{P}$ em arroz são dependentes da condição de avaliação (solo e in vitro) e da dose de P utilizada;

b) Em solo, no nível baixo de P, a altura da planta e o número de raízes da planta são as caraterísticas que têm maior efeito direto na eficiência de utilização do P. Por outro lado, no nível alto de P, o número de folhas e o comprimento das raízes da planta são as caraterísticas que têm maior efeito direto na eficiência de utilização do P;

c) In vitro, tanto no baixo como no alto nível de $\mathrm{P}$, o teor de $\mathrm{P}$ acumulado e o volume da raiz são as caraterísticas que têm maior efeito direto na eficiência de $\mathrm{u}$ tilização do P;

d) Na condição em solo, na seleção de plantas eficientes na utilização do $\mathrm{P}$ em solos pobres nesse nutriente, ênfase deve ser dada na altura da planta (maior) e número de raízes (menor), ao passo que em solos ricos, maior ênfase deve ser dada ao número de folhas (maior) e ao comprimento da raiz (maior);

e) $\mathrm{Na}$ condição in vitro, na seleção de plantas eficientes na utilização do $\mathrm{P}$ em baixa concentração, ênfase deve ser dada na acumulação de P pela planta (menor) e no volume da raiz (menor), enquanto em alta concentração, maior ênfase deve ser dada à acumulação de $\mathrm{P}$ pela planta (menor) e ao volume da raiz (maior).

\section{REFERÊNCIAS BIBLIOGRÁFICAS}

BARBOSA FILHO, M. P. Adubação do arroz de sequeiro. Informe Agropecuário, Belo Horizonte, v. 14, n. 161, p. $32-38,1989$.

CALDAS, L. S.; HARIDASAN, P.; FERREIRA, M. E. Meios nutritivos. In: TORRES, A. C.; CALDAS, L. S.; BUSO, J. A. (Eds.). Cultura de tecidos e transformação genética de plantas. Brasília: Embrapa-SPI/CNPH, 1998. v. 1, p. 87-132.

CHANG, T. T.; LORESTO, G. C.; O'TOOLE, J .C.; ARMENTA-SOTO, J. L. Strategy and methodology of breeding rice for drought-prone areas. In: IRRI. Drought resistance in crops with emphasis on rice. Los Baños: [s.n.], 1982. p. 217-244.

CLARK, R. B.; DUNCAN, R. R. Improvement of plant mineral nutrition through breeding. Field Crops Research, Amsterdam, v. 27, p. 219-240, 1991.

EMBRAPA. Serviço Nacional de Levantamento e Conservação de Solo. Manual de métodos de análise de solo. 2. ed. Rio de Janeiro, 1997. 212 p.

FAGERIA, N. K. Adubação e nutrição mineral da cultura de arroz. Rio de Janeiro: Campus; Goiânia: Embrapa-CNPAF, 1984. 341 p.

FAGERIA, N. K. Nutrição mineral. In: VIEIRA, N. R. de A.; SANTOS, A. B. dos; SANT'ANA, E. P. (Eds.). 
A cultura do arroz no Brasil. Santo Antônio de Goiás: Embrapa Arroz e Feijão, 1999. p. 173-196.

FAGERIA, N. K. Nutrient use efficiency in crop production. In: Maximizing crop yields. New York: Marcel Dekker, 1992. p. 125-163.

FAGERIA, N. K. Resposta de cultivares de arroz a fertilizante fosfatado em Latossolo Vermelho-Escuro no Brasil Central. Revista Brasileira de Ciência do Solo, Campinas, v. 15, n. 1, p. 63-67, 1991.

FAGERIA, N. K.; BARBOSA FILHO, M. P. Avaliação de cultivares de arroz em função de suas tolerâncias ao baixo nível de fósforo disponível do solo. Revista Brasileira de Ciência do Solo, Campinas, v. 6, n. 2, p. 146$151,1982$.

FAGERIA, N. K.; WRIGHT, R. J; BALIGAR, V. C. Rice cultivar evaluation for phosphorus use efficiency. Plant and Soil, Hague, v. 111, n. 1, p. 105-109, 1988.

FURLANI, A. M. C.; BATAGLIA, O. C.; FURLANI, P. R.; AZZINI, L. E.; CAMARGO, O. B. Avaliação de genótipos de arroz quanto à eficiência na utilização de fósforo em solução nutritiva e em solo. Revista Brasileira de Ciência do Solo, Campinas, v. 7, n. 3, p. 291303, 1983.

FURLANI, P. R.; FURLANI, A. C. M. Tolerância a alumínio e eficiência a fósforo em milho e arroz: características independentes. Bragantia, Campinas, v. 50, n. 2, p. 331-340, 1991.

GOMEZ, K. A.; GOMEZ, A. A. Statistical procedures for agricultural research with emphasis on rice. Los Baños: IRRI, 1976. 294 p.
IITA (Nigeria). IITA research highlights for 1981. Ibadan, 1982.

MORAES, J. F. V.; RABELO, N. A. Um método simples para a digestão de amostras de plantas. Goiânia: Embrapa-CNPAF, 1986. 12 p. (Embrapa-CNPAF. Documentos, 12).

MURASHIGE, T.; SKOOG, F. A revised medium for rapid growth and bioassays with tobacco tissue cultures. Physiologia Plantarum, Copenhagen, v. 15, p. 473497, 1962.

SANT'ANA, E. V. P. Associação genética entre características da parte aérea e do sistema radicular em arroz de sequeiro. In: ENCONTRO DE GENETICISTAS GOIANOS, 2., 1994, Goiânia. Anais... Goiânia: UFG, 1994.

SANT'ANA, E. V. P. Comportamento de genótipos de arroz (Oryza sativa $L$.) de terras altas em dois níveis de fósforo em solo e in vitro. 2000. 143 p. Dissertação (Mestrado em Agronomia) - Universidade Federal de Goiânia, Goiânia.

VENCOVSKY, R.; BARRIGA, P. Genética biométrica no fitomelhoramento. Ribeirão Preto: Sociedade Brasileira de Genética, 1992. 392 p.

YOSHIDA, S.; FORN, D. A.; COCK, J. H.; GOMES, K. A. Laboratory manual for physiological studies of rice. Los Baños: IRRI, 1976. 